\title{
CONTRAST SENSITIVITY OF THE HUMAN PERIPHERAL RETINA 1
}

\author{
J. M. DAITCH and D. G. GREEN \\ Department of Ophthalmology, University of Michigan, Ann Arbor, Michigan 48104
}

(Received 24 Jamuary 1969)

THE CAPACITY of the eye to appreciate detail in a distant object is determined by both the size and contrast of the detail. The effects of contrast on visual resolution are conveniently measured in terms of the threshold contrasts for detecting sinusoidal gratings. These variable contrast targets, first used by SCHADE (1956) to measure visual acuity, have an intensity distribution that varies sinusoidally with distance across the bars of the pattern. Recently, ENROTH-CUGELL and ROBSON (1966) have recorded the responses of single ganglion cells of the cat's retina to sinusoidal gratings that drifted across the cell's receptive field. The contrast sensitivity functions of single units were determined by adjusting the contrast so that the drifting grating evoked a criterion response.

Superficially, the contrast sensitivity measured on individual cells appears similar to the psychophysically determined contrast sensitivity of the human eye. Both show a spatial frequency of optimum sensitivity with a fall in sensitivity at higher and lower spatial frequencies. Detailed comparisons between the psychophysical and the single unit contrast sensitivity functions indicate important differences (ENROTH-CUGELL and ROBSON, 1966). Firstly, they occupy very different positions along the spatial frequency axis. The cat ganglion cells have an optimum sensitivity at a spatial frequency which is about an order of magnitude lower than that of the human observer using central fixation. Secondly, the single unit contrast sensitivity functions have a different shape from the human contrast sensitivity functions. The human measurements can be fit with the difference of two exponential functions (CAMPBELL and GREEN, 1965) while the cat contrast sensitivity function is described by the difference between two Gaussian functions.

The human measurements used in making the above comparisons, however, were obtained with subjects using central fixation, and we wondered how the contrast sensitivity of the human peripheral retina, which might be more like the cat retina, would compare with the contrast sensitivity functions recorded from single units in the cat. For this reason a series of measurements of the contrast sensitivity of the peripheral retina have been made. Since it seemed likely to us that the peripheral human retina would have fewer rods than the retina of the cat, which has one-third as many cones as the human retina (WALLs, 1942), the Stiles-Crawford effect (STILES, 1939) was utilized in order to further increase the rods' role in vision.

\section{METHOD}

The test field was a vertical, sinusoidal grating pattern formed upon the face of a cathode-ray oscilloscope (Tektronix type 544 with a P31 green phosphor) using the technique described in detail by CAMPBELL and GREEN (1965). The test field, located $12^{\circ}$ in the temporal retina, measured $8 \times 3^{\circ}$. To avoid the problem that feebly

1This work was assisted by National Institutes of Health USPHS Grant NB 07579 . One of the authors (J.M.D.) was supported by a student fellowship under Grant NB 05163. 
visible objects seen extrafoveally tend to fade, the test was presented in a flash for a duration of $200 \mathrm{msec}$ each sec. The luminance of the test field was varied by neutral density fitters placed in front of the oscilloscope. A Wratten \#65 filter placed in front of the oscilloscope modified the dominant wavelength of the phosphor so that it approached the $K_{\max }$ in sensitivity of the rods.

The subject's head was firmly held by a bite bar. In all tasks the subject steadily fixated on a small light located $12^{\circ}$ from the center of the target, thus insuring that the center of the test field was 12 in the peripheral retina.

The subject viewed the gratings through a $1 \mathrm{~mm}$ artificial pupil. The artificial pupil was decentred parallel to the lines of the grating (vertically) by about $3 \mathrm{~mm}$. The threshold contrast was greatly increased by moving the artificial pupil as little as $1 \mathrm{~mm}$ horizontally in either direction from the centered position, while moving the artificial pupil vertically had only slight effect on the contrast sensilivity function. It was thus possible to use the Stiles-Crawford effect to decrease the sensitivity of the cones and to simultaneously avoid the Campbell effect (CAmpbell, 1958).

A $6.8 \mathrm{log}$ troland-sec bleach was used occasionally in order to differentiate rod and cone contributions to the contrast sensitivity functions. The bleaching field, seen in Maxwellian view, was in the shape of a hemisphere with a radius of $7^{\circ}$ and was positioned so that the test would be in the center of the field. Dark adaption curves were measured after the bleach in order to determine the times for full cone recovery and for the rod-cone break.

\section{PROCEDURE}

The subject's right eye was dilated by two drops of either $0.5 \%$ Mydriacyl (tropicamide) or $0.5 \%$ Cyclogyl (cyclopentolate hydrochloride). The specific mydriatic used did not significantly affect the subject's responses. A lens was selected to give maximum visual acuity and was placed in front of the artificial pupil. Subject J. D. required a $-1.75 \mathrm{D}$ lens, while subject M. M. needed a - 3.0D lens.

The subject dark adapted for $30 \mathrm{~min}$ prior to beginning the contrast sensitivity measurements. The test luminance covered a range of four density units, and the luminance was increased from the lowest to the highest by half density unit increments. At each luminance level the spatial frequency was increased from $0.5 \mathrm{cycles} / \mathrm{deg}$ until the subject could no longer see the grating at unit contrast. The subject varied the contrast, at each frequency, until he could just see that the test was not a uniform field but consisted of vertical bars.

\section{RESULTS}

Figure 1 shows the contrast sensitivity of the peripheral retina of subject J. D. measured at several luminances. The contrast sensitivity of the peripheral retina, measured psychophysically on two observers, could be approximated by the difference of two Gaussian functions (sce Fig. 1). Enroth-Cugell and Robson have reported that contrast sensitivity measurements from electrophysiological recordings of the responses of the ganglion cells of cats to sinusoidal gratings could also be expressed as the difference of two Gaussian functions. These workers fitted their measurements with a formula which enabled them to calculate what they termed the characteristic radii of the center and antagonistic surround. They used a formula of the form.

$$
S(v)=K_{1} e^{\left(r_{c} v\right)^{2}}-K_{2} e^{\left(r_{s} v\right)^{2}},
$$

where $S(v)$ is contrast sensitivity, the parameters $K_{l}$ and $K_{2}$ are constants, $r_{c}$ is the radius of the center, $r_{s}$ is the radius of the surround, and $v$ is the frequency. Using equation (1), the parameters $r_{c}$ and $r_{s}$ (the characteristic radii) and $K_{l}$ and $K_{2}$ (the sensitivity parameters) were calculated. As shown in Figs. 2 and 3, these characteristic radii generally decrease by about a factor of 2 for a $4.0 \log$ unit increase in luminance, while the sensitivity parameters increase with increasing luminance.

It is well known that rods and cones have different visual acuity characteristics. 


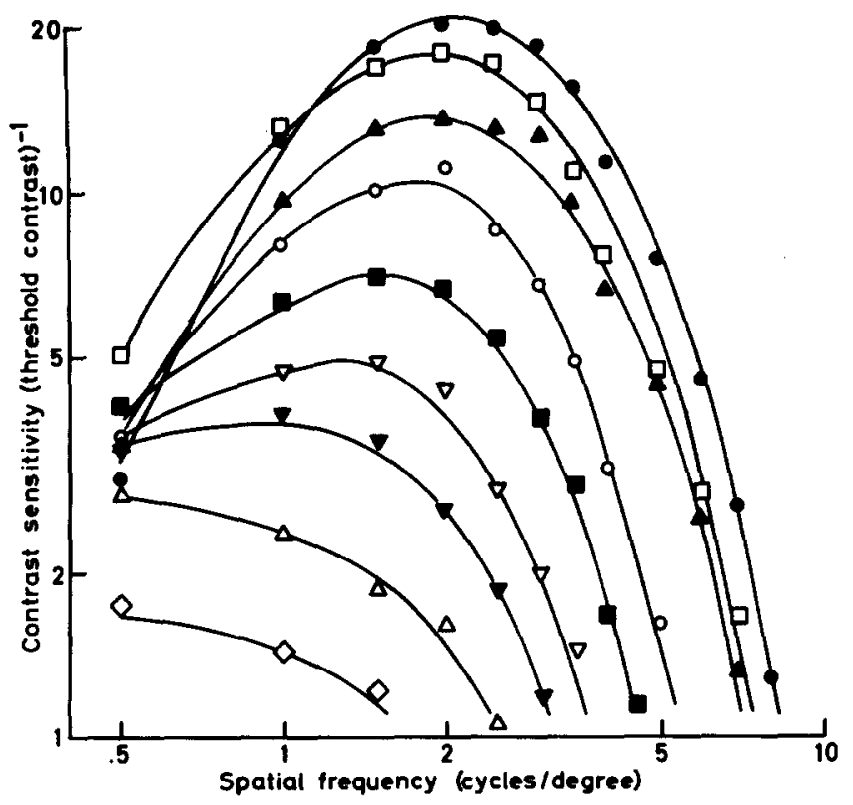

FIG. 1. Contrast sensitivity of the peripheral retina at varying luminances and spatial frequencies. The target measured $8 \times 3^{\circ}$ and was located $12^{\circ}$ in the temporal retina. Contrast was defined in the usual way as being $I_{\max }-I_{\min }$. The smooth curves are the empirically fitted difference of two $I_{m a x}+I_{\min }$.

Gaussian functions. Each symbol is the average of twelve measurements except for the target at a luminance of $1.5 \mathrm{log}$ trolands, where each is the average of sixteen measurements. The target produced a mean retinal illumination of: $0,1.5 \log \mathrm{td} . ; \bigsqcup, 1.0 \log \mathrm{td} . ; \mathbf{\Delta}, 0.5 \log \mathrm{td} . ; \bigcirc, 0.0 \log \mathrm{td}$.;

$\square,-0.5 \log \mathrm{td} . ; \nabla,-1.0 \log \mathrm{td} . ; \nabla,-1.5 \log \mathrm{td} . ; \Delta,-2.0 \log \mathrm{td} . ;\langle,-2.5 \log \mathrm{td}$.

Measurements of visual acuity versus intensity usually show a point of inflection indicating a transition from rods to cones. However, the results in Fig. 1 show no clear indication of passage from scotopic to photopic vision. Which receptors are signalling the presence of the grating at each luminance level? To answer this question, the unmodulated and flashing test field was used to measure the time course of dark-adaptation after a strong bleach. It was found that the photopic phase of dark-adaptation lasted for more than $10 \mathrm{~min}$. The cones recovered fully in about 6 min so that there was a period between 6 min and the start of the rod phase of dark-adaptation during which the cones are recovered and the rod thresholds are above those of the cones.

At the highest luminance, the threshold contrasts for resolving the sinusoidal gratings measured between 6 and $10 \mathrm{~min}$ after the bleach were indistinguishable from those measured after $30 \mathrm{~min}$ of dark-adaptation. It therefore seems likely that only cones signal the presence of the target at the highest luminance levels. The target of lowest luminance is about $2.0 \mathrm{log}$ units below cone threshold and about $0.75 \mathrm{log}$ units above rod threshold. Consequently, it seems likely that the low-level targets stimulate only rods. The absolute threshold of the fully recovered cones, as measured between 6 and 10 min after the bleach, using the uniformly illuminated test field was 0.32 trolands (subject J. D.). All brighter visual acuity targets are not necessarily detected by cones alone. It was found that at all spatial frequencies above $0.5 \mathrm{cycle} / \mathrm{deg}$ a grating of unit contrast, which produced a mean retinal illumination of 1.0 trolands, could not be seen as a striped pattern between 6 and 


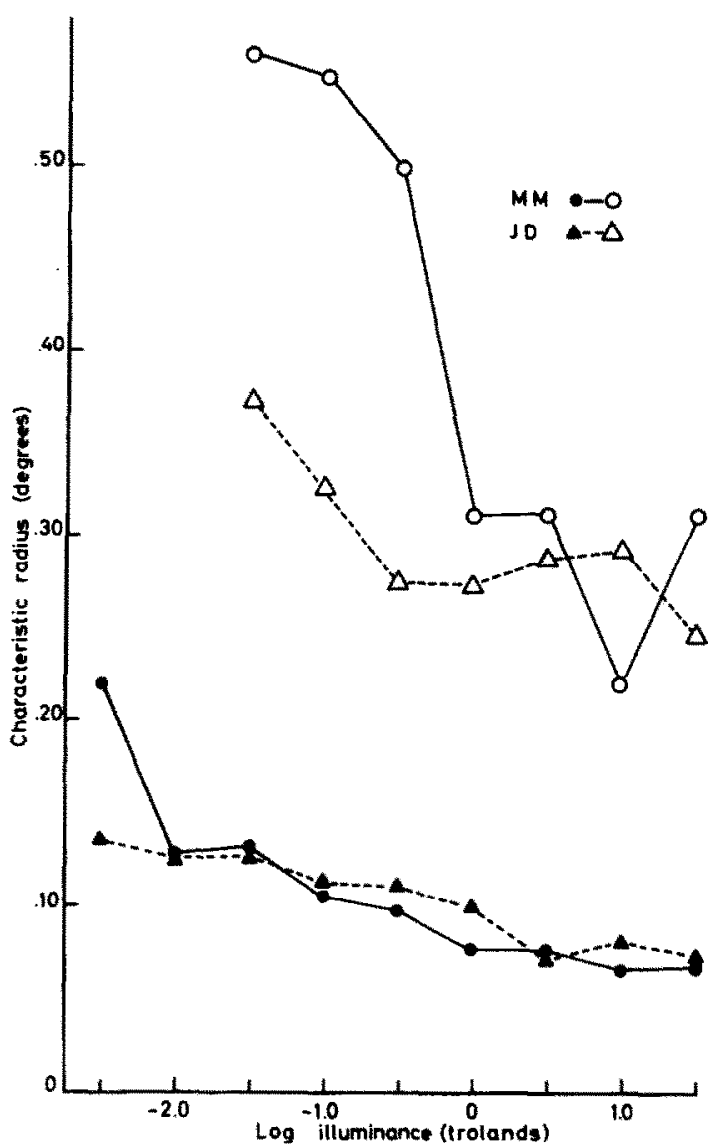

FIG. 2. Characteristic radii of the center and the surround calculated from equation 1 at various retinal illuminances using the smooth curves shown in Fig.1. The radii for subject M.M. are from results similar to those in Fig. 1 but obtained from the average of four measurements. The filled symbols are the radii of the center, while the open symbols are the radii of the surround.

10 min after the bleach. Thus, it seems that the bars of this target had to stimulate rods before it could be detected.

\section{DISCUSSION}

ENROTH-CUGELL and ROBSON (1966) have shown that the low-frequency decrease in contrast sensitivity of a single ganglion cell is due to the lateral inhibitory effect upon the activity of the cell, produced by the periphery of a cell's receptive field. If the low-frequency decrease in the human contrast sensitivity function is attributed to the effects of an antagonistic surround in the receptive field of cells within the visual system, it is possible to correlate the present findings with results obtained on single cells. Recordings made on single units from the retina of the cat indicate that the lateral inhibitory interactions disappear at very low light levels (BARLow, FITZHUGH and KuFfLer, 1957; ENROTHCUGELl and ROBSON, 1966). This correlates with the disappearance of the low-frequency decrease in sensitivity we find for human vision at low luminance levels. In addition, as has been reported for inhibitory interactions in single cells in the cat, the appearance of a low- 


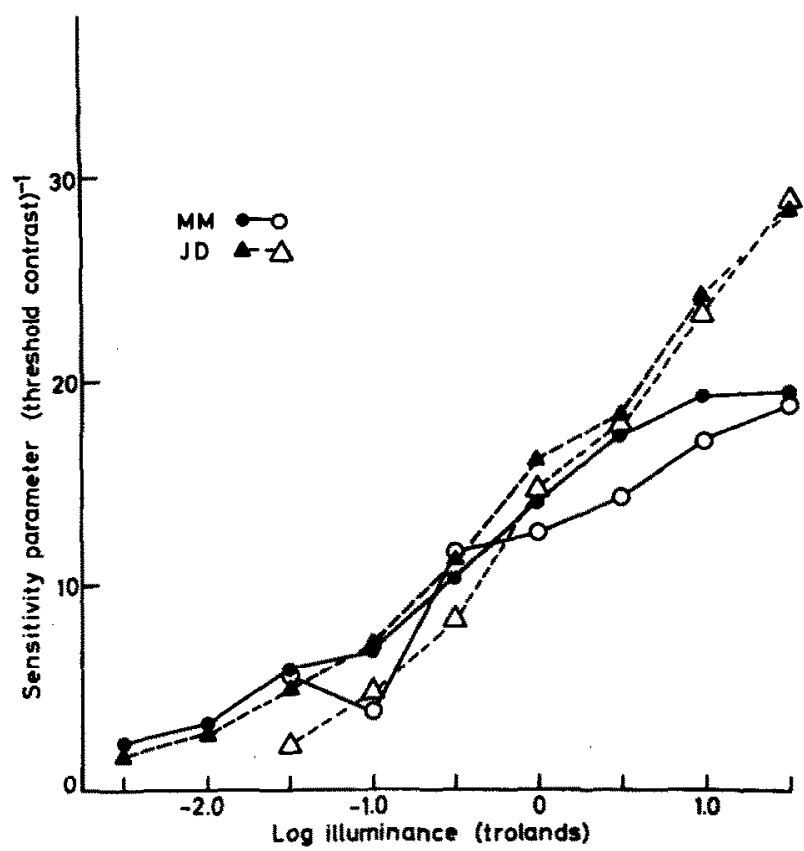

Frg. 3. Contrast sensitivity of the human peripheral retina. Sensitivity parameters of the center and the surround used in fitting smooth curves to the contrast sensitivity measurements. The filled symbols are the sensitivity parameters of the center; the open symbols are the sensitivity parameters of the surround.

frequency fall-off at higher light levels does not seem to be related to the transition from one receptor type to another.

How do the contrast transfer functions (ctf's) measured directly on single retinal ganglion cells (ENROTH-CUGELL and ROBSON, 1966) compare with the psychophysically derived ctf's of the human visual system? CAMPBELL and ROBSON (1968) have suggested that the human visual system behaves as a series of independent channels consisting of narrowband spatial filters 'tuned' to different spatial frequencies. Further, they suggest that the $\mathrm{ctf}$ of the overall visual system is the envelope of the ctf's for the individual channels. On the basis of cat ganglion cell ctf's, Enroth-Cugell and Robson have argued that a band-pass type of ctf is already established at the level of the retina. However, if the frequency selective filtering takes place in the retina, the Campbell and Robson notions seem to require that at least some of the retinal ganglion cells have more sharply tuned ctf's than the ctf of the overall system. Both the results in Fig. 1 and the ctf's from cat retinal ganglion cells have the property that $K_{I} / K_{2}$ is close to unity. Therefore, the ratio of the radius of the surround to the radius of the center, $r_{s} / r_{c}$, defines a parameter that can be used to characterize the relative narrowness of the ctf's. The smaller the value of $r_{s} / r_{c}$, the narrower is the ctf. In the cat $r_{s} / r_{c}$ measured on 21 cells ranged from 2.5 to 23 , while for the human peripheral retina at the highest luminance levels used in this study $r_{s} / r_{c}$ was about 3 for both of our observers.

In the cat experiments a $3.5 \mathrm{~mm}$ dia. pupil and a target luminance of $16 \mathrm{~cd} / \mathrm{m}^{2}$ was used. In the present experiments the target had a mean luminance of about $40 \mathrm{~cd} / \mathrm{m}^{2}$ and was viewed through a $1 \mathrm{~mm}$ dia. pin-hole pupil. Thus, the illumination falling on the cat retina was probably greater than the retinal illumination produced by the brightest target used in this study. Yet, the results seem to show that at both scotopic and photopic luminances the 
human ctf's measured in the peripheral retina are similar in shape to, and not broader than, the contrast sensitivity functions for individual retinal ganglion cells of the cat. While any similarities between psychophysical results and properties of single units in the cat may be coincidental, the above arguments seem to suggest that channels selectively tuned to different spatial frequencies, if they exist within the visual system, have not yet been established at the retinal ganglion cell level.

\title{
REFERENCES
}

Barlow, H. B., Fitzhugh, R. and Kuffrer, S. W. (1957). Changes of organization in the receptive fields of the cat's retina during dark adaption. J. Physiol. 137, 338-354.

Campbell, F. W. (1958). A retinal acuity direction effect. J. Physiol. 144, 25-26P.

Campbell, F. W. and Green, D. G. (1965). Optical and retinal factors affecting visual resolution. J. Physiol. $181,576-593$.

Campbell, F. W. and Robson, J. G. (1968). Application of a Fourier analysis to the visibility of gratings. J. Physiol. 197, 551-566.

Enroth-Cugell, C. and Robson, J. G. (1966). The contrast sensitivity of retinal ganglion cells of the cat. $J$. Physiol. 187, 517-552.

Schade, O. H. (1956). Optical and photoelectric analog of the eye. J. opt. Soc. Am. 46, 721-739.

Stiles, W. S. (1939). The directional sensitivity of the retina and the spectral sensitivities of the rods and cones Proc. R. Soc. B 127, 64-105.

Walls, G. L. (1942). The Vertebrate Eye and Its Adaptive Radiation, The Cranbrook Institute of Science, Bloomfield Hills, Michigan.

\begin{abstract}
Threshold contrasts were measured psychophysically for a sinusoidal grating target centered $12^{\circ}$ in the peripheral retina. The relationship between contrast sensitivity, the reciprocal of the threshold contrast, and the spatial frequency of the gratings can be adequately described by the difference of two Gaussian functions. The parameters of the fitted Gaussians are used to describe the effects of varying the mean luminance of the target on the shape of the contrast sensitivity function. With increasing luminance the characteristic radii-parameters which are related to the width of the spread function of the visual system-decrease. while the overall contrast sensitivity of the eye increases
\end{abstract}

Résumé-On mesure psychophysiquement le seuil de contraste pour un réseau sinusoidal vu à $12^{\circ}$ en rétine périphérique. On peut décrire correctement par la différence de deux fonctions de Gauss la relation entre la sensibilité au contraste, la réciproque des seuils de contraste et la fréquence spatiale des réseaux. On utilise les paramètres des gaussiennes pour décrire l'effet de la variation de la luminance moyenne du test sur la forme de la fonclion de sensibilité au contraste. Quand la luminance croît. les paramètres de rayons caractéristiques liés à la largeur de la fonction d'étalement du système visuel diminuent, tandis que la sensibilité globale au contraste de l'oeil augmente.

Zusammenfassung-Kontrastschwellen wurden mittels eines Sinusgitters, welches auf 12 in der Netzhautperipherie zentriert war, psychophysikalisch bestimmt. Der Unterschied zwischen zwei Gausschen Fehlerfunktionen kann dem Verhältnis zwischen Kontrast-empfindlichkeit, dem Reziprozitätswert der Kontrastwschwelle, und der Raumfrequenz der Gitter genugten. Die Parameter der berechneten Gausschen Funktionen werden zur Beschreibung des Einflusses der durchschnittlichen Leuchtdichte des Prüflichtes auf die Form der Kontrastempfindlichkeitsfunktion behützt. Eine Beleuchtungsverstärkung führt $\mathrm{zu}$ einer Verringerung der kennzeichnenden Radien, welche im Verhältnis zur Grösse der Streuungsfunktion des Sehapparates stehen, während sich die gesamte Kontrastempfindlichkeit des Auges vergrössert.

Резюме - Проведено психофизическое измсрсние пороговых контрастов для синусондальной решетки, расположенной (центрированной) в $12^{\circ}$ от точки фиксации на периферии сетчатки. Различие в двух Гауссианах удовлетворительно отвечает отношенню между контрастной чувствительностью (величнной обратной пороговым контрастам) и пространственной частотой решетки. Параметры приведенных Гауссиан используются для описания влияния, оказываемого изменением средней яркости объекта на форму кривой контрастной чувствительности. С увеличением яркости характерные радиальные параметры - связанные с величиной функции дисперсии зрительной системы - уменьшаются, в то время как общая контрастная чувствительность глаза увеличивается. 